http://jmscr.igmpublication.org/home/

ISSN (e)-2347-176x ISSN (p) 2455-0450

crossref DOI: https://dx.doi.org/10.18535/jmscr/v7i7.139

\title{
Peripartum cardiomyopathy with preeclampsia and type II diabetes mellitus: overlapping diseases of pregnancy
}

Authors

\author{
Nikita Pahuja, Gaurav Sachdeva, Aditya Chaudhary
}

NC Medical College, Israna, Panipat

\begin{abstract}
Peripartum cardiomyopathy (PPCM) is a serious cardiac disorder occuring late in pregnancy or early postpartum period in absence of infections, metabolic, toxic, ischaemic or valvular causes of myocardial dysfunction. Preeclampsia, multifetal gestation and diabetes have been strongly associated with PPCM. We are presenting a case of peripartum cardiomyopathy in 29 years old primigravidae at 36 weeks gestation with triplet who presented to us with gestational diabetes with superimposed preeclampsia.

Keywords: Peripartum cardiomyopathy, pregnancy, preeclampsia, diabetes.
\end{abstract}

\section{Introduction}

PPCM is a syndrome with symptoms of heart failure and signs of left ventricular systolic dysfunction, which manifest between the last month of pregnancy and the first 5 months postpartum $^{[1]}$. Its incidence varies from $0.2 \%$ to $3 \%$ live births ${ }^{[1-3]}$ and from region to region worldwide. The prognosis is generally good in the majority of cases although some patients progress to irreversible heart failure, heart transplantation or death $^{[3,4]}$.

However, the National Heart, Lung, and Blood Institute and the Office of Rare Diseases in the year 2000 laid down certain criteria for its diagnosis $^{[1]}$.The criteria for diagnosing PPCM are:

1. Development of cardiac failure in the last month of pregnancy or within five months of delivery,

2. Absence of an identifiable cause for the cardiac failure,
3. Absence of recognizable heart disease before the last month of pregnancy, and

4. Left ventricular (LV) dysfunction (ejection fraction of less than $45 \%$ or reduced shortening fraction $)^{[1]}$.

An error in diagnosis is life threatening for the patients with a potential for fatal outcome in about $20 \%$. in view of this a case of peripartum heart failure was subsequently diagnosed as peripartum cardiomyopathy.

\section{Case Report}

29 years old pimigravida unbooked patient at 36 weeks period of gestation with triplets reported to casualty with sudden acute dyspnea and abdominal pain. Her documents revealed that she is a known case of type 2 diabetes mellitus with preeclampsia. No family history of pre eclampsia. Her mother is a known diabetic. On examination, she was found to have pulse-140/min, B.P180/140mmhg, SPO2 -88\% room air. Obstetric 
examination revealed uterus over distended, firm, non tender with multiple fetal parts felt, FHSI 132 /min ,FHS II-140/min, FHS III-144/min. Internal examination revealed cervical os closed, uneffaced. Urine albumin was 2+. All investigations were within normal limits. Patient was taken up for emergency LSCS in view of uncontrolled BP and multifetal gestation. Alive triplets were delivered with baby weight of $1^{\text {st }}$ $2.1 \mathrm{~kg}, 2^{\text {nd }}-1.8 \mathrm{~kg}$ and $3^{\text {rd }} 1.7 \mathrm{~kg}$. Patient was shifted to ICU and managed conservatively on the lines of pulmonary odema with inj furosemide and ventilator support. BP was controlled on inj labetalol and blood sugar was controlled by Iv insulin. Investigations in ICU revealed radiological evidence of pulmonary oedema, rest all investigations were within normal limits. On post-op day 2 patient was weaned off from ventilator after resolution of pulmonary oedema. 2D echo was done which showed ejection fraction of $32 \%$.She was continued on diueretics, digoxin, ACE inhibitors, anti diabetic medication and discharged on post op day 10 after stich removal. 2D echo was repeated after 1 month which showed improved ejection fraction. Based on the progress and clinical events diagnosis of PPCM was made.

\section{Discussion}

The incidence of PPCM is quoted to be varying from 1 in 15000 to 1 in 4000 deliveries, $75 \%$ present within the first month and $45 \%$ in the first week postpartum. ${ }^{[1][5]} \mathrm{Up}$ to $7 \%$ may present in the last trimester of pregnancy. Risk factors include advanced maternal age, multiparity, multiple gestation, obesity, gestational hypertension, preeclampsia and black race. ${ }^{[5][6]}$

Although the left ventricle may not be dilated, the ejection fraction is nearly always reduced below $45 \%$. Peripartum cardiomyopathy usually presents with symptoms of worsening cardiac failure. These include dyspnoea on exertion, fatigue, ankle oedema, embolic phenomena, atypical chest pains and haemoptysis. Examination may reveal evidence of a raised CVP, tachycardia, cardiomegaly with a gallop rhythm (S3), mitral regurgitation, pulmonary crackles and peripheral oedema. Chest radiographs may show cardiomegaly with pulmonary oedema and pulmonary venous congestion.

The clinical presentation and haemodynamic features in PPCM are indistinguishable from those of other forms of dilated cardiomyopathy. The clinical course of PPCM varies with approximately $50-60 \%$ patients showing complete or near complete recovering of clinical status and cardiac function, usually within the first 6 months postpartum. The remaining patients demonstrate either continued clinical deterioration leading to early death or persistent left ventricular dysfunction and chronic heart failure. There appears to be an initial high risk period with amortality of $25-50 \%$ in the first 3 months postpartum. Patients with persistent cardiomegaly at 6 months have a reported mortality of $85 \%$ at 5 years. ${ }^{[7],[9],[10]}$ Subsequent pregnancies in women with PPCM are often associated with relapses and high risk for maternal morbidity and mortality. For this reason subsequent pregnancy should be discouraged in women with PPCM who have persistent cardiac dysfunction. ${ }^{[7-10]}$

\section{Conclusion}

PPCM is a rare disease of unknown etiology may be associated with higher mortality rate. Survival rate depends on the accurate diagnosis ad vigorous treatment.

\section{References}

1. Pearson GD, Veille JC, Rahimtoola S, et al. Peripartum cardiomyopathy: National Heart, Lung and Blood Institute and Office of Rare Diseases Workshop recommendations and reviews. JAMA. 2000;283(9):1183-8. [PubMed]

2. Fett JD, Christie LG, Carraway RD, Murphy JG. Five-year prospective study of the incidence and prognosis of peripartum cardiomiopathy at a single insitution. Mayo Proc. 2005;80(12):1602-6[PubMed] 
3. Brar S, Khan S, Sandhu G, et al. Incidence, mortality and racial differences in peripartum cardiomyopathy. Am J Cardiol. 2007;100:302-4. [PubMed]

4. Elkayam U, Akhter MW, Singh H, et al. Pregnancy-associated cardiomyopathy. Clinical Characteristics and a comparison between early and late presentation. Circulation. 2005;111(16):2050 [PubMed]

5. Cunningha GF, Gant NF, Leveno KJ, Gilstrap IIILC, Hauth JC, Wenstrom KD, editors. Willia ms Obstetrics. $21^{\text {st }}$ ed. New York: McGraw-Hill; 2001. p. 1141514

6. Libby P, Bonow RO, Mann DL, Zipes DP, editors. Braunwald's heart disease: A textbook of cardiovascular medicine. $8^{\text {th }}$ ed. Philadelphia, PA: Saunders; 2007

7. Michael de swiet. Heart disease in pregnancy. In: Michael de swiet. Editor.Medical disorders in obstetric practice. $4 \mathrm{t} \mathrm{h}$ edition,Blackwell Scientific Publication 2002; 144-46.

8. F Garry Cunningham, Kenneth J Leveno, Steven L Bloom et al. Cardiovascular diseases. In: Dwight Rause, Bill Rainey, Cathy Spong, George Vendel Jr, editors. Williams Obsterics. $22^{\text {nd }}$ edition. Mc Graw Hill 2005: 1030-32.

9. Vinod Sharma. Peripartum Cardiomyopathy. Cardiology Today; MayJune 2004; 8(3): 127-29.

10. Carvallo A, Brandao A et al. Prognosis in peripartum cardiomyopathy. Am J Cardiol; 1989; 64; 540-42. 